\title{
Using Computer Output As A Vehicle For Self-Directed Study Of Financial Theory: The Art Of Teaching Backwards
}

Robert D. Campbell, Hofstra University, USA

\begin{abstract}
This paper presents an example of an approach to teaching financial theory at the college and post-graduate levels that I call "teaching backwards". In the more traditional approach, instructors begin by explaining financial theory, then proceed to give examples of the way this theory can be applied to a business problem, structuring data around the predetermined theory. When teaching backwards we reverse the process, suggesting various ways to organize and report data related to a business problem and then inviting students to analyze these data to identify relationships between the variables that enable them to see potential applications of financial theory, or even to discover the theory itself. The example presented employs computer modeling and computer simulation as essential enabling tools for self-directed learning.
\end{abstract}

Keywords: Computer Simulation; Computer Modeling; Economics; Financial Theory; Real Estate Finance; SelfDirected Learning

\section{INTRODUCTION}

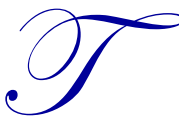

his paper presents an example of an approach to teaching financial and economic theory at the college level that I call "teaching backwards". I begin by presenting a common business problem, that of structuring debt financing for a real estate investment. Using the more traditional approach (teaching frontwards), the instructor will first take pains to explain the fundamental financial theory that bears upon the selection of the optimal financial choice, and then recommend appropriate computer output designed around this theory and intended to demonstrate it.

The fundamental idea of teaching backwards is to reverse this process. At the outset, the instructor invests little time and effort to the task of explaining financial theory. Instead, he or she encourages students to begin with computer output, output that may disregard financial theory, and instead is intended to model important investor outcomes under different economic states of the world. The student then engages in a self-directed learning process in which he allows the data itself to lead him back to an understanding of the underlying financial processes that produce the observed outcomes.

\section{The Business Problem}

Students analyze the choice between two financing options for a real estate investment: 1) An Adjustable Rate Mortgage (ARM), or 2) A Fixed Rate Mortgage (FRM). Investors typically encounter this kind of decision when structuring debt financing in real estate.

The ARM will always carry a lower initial rate - in this case it is $5.0 \%$-- but the ARM has an important disadvantage in that the interest rate can increase later if market rates rise. At the same time, the ARM rate may decline if market rates fall. The FRM has a higher initial rate of $6.0 \%$, but it has the advantage that the rate will not rise, even if market rates increase. At the same time, FRM borrowers cannot benefit if market rates decline. 
At first blush, the analysis appears to be straightforward, and an excellent opportunity to apply traditional teaching frontwards: 1) Model the cost of the mortgage under different possible prevailing future market rates, 2) Decide what you expect future market rates to be, and 3) Choose the financing option with the lower cost in the expected future state of the market. It sounds logical enough, and many analysts will proceed in just that way; but to do so is to overlook two serious complications that are critically important to making the best decision.

\section{Two Important Complications}

There exist two serious complications that compromise the efficacy of the straightforward analysis described above. To understand these, we must first understand the investment outcomes that will be the primary focus for real estate investors. Real estate investors are not primarily focused on cost of capital per se. Instead, their primary focus is return on equity investment (ROI). The determinants of debt financing costs are reasonably straightforward, but the determinants of ROI are far more complex. Investors will not be very concerned if debt financing costs rise, if this change is accompanied by an increase in ROI; and that is a situation that can occur in real estate, and often does.

In real estate investment, two important outcomes are affected by changes in market rates, not just one. If interest rates increase, it will probably be because of anticipated price changes, commonly called inflation (Fisher, 1930). If the investor uses the ARM and debt markets anticipate increased prices, the rate on the ARM will rise and financing costs will rise with them, negatively affecting investor returns. But something else will also happen: As price levels rise, in most cases we will expect rents to rise with them, increasing rental income and favorably influencing real estate investment returns. Thus, in this situation we have two important variables that bear critically upon investment outcomes, and that respond to changing economic conditions in ways that are not independent of each other. Such is often the case in business finance, and this circumstance lends itself to an approach to analysis called Monte Carlo Modeling (See, for example: Haney, 2016). Monte Carlo modeling is heavily dependent on computer output. It is very difficult to explain or to quantify the combined result of two variables that are functionally related to each other, but are responding to a common cause variable in different ways.

The second important feature that complicates straightforward traditional analysis is this: two different returns on investment are important to real estate owners, not just one. Current Returns are returns that recur annually when revenues exceed expenses. Total Returns include capital gains, which in real estate normally comprise a very important source of returns, in many cases most of it. Changing economic conditions will affect both of these returns, but in different ways, and it is very difficult to quantify or to explain the nature of that interaction.

In sum, we have a complex set of economic interactions leading to a set of financial outcomes that are difficult or impossible to clearly explain and extremely difficult to quantify when we attempt to teach frontwards. The proposed solution is to teach backwards instead.

\section{Teaching Backwards}

Teaching backwards, we take a naïve approach to the financial theory underlying the investment outcomes. Instead, we look at the primary variables of interest, and structure computer output around these variables, giving little thought as to the way in which these outcomes develop.

In this case, we know we must make a recommendation regarding our mortgage financing. We also know that the critical variable affecting the outcome for that choice is the future level of interest rates. Further, we know that the determining influence on interest rates will be the anticipated rate of inflation. Therefore, we place possible future levels of price inflation and the implied future ARM interest rates in the left column of our summary.

We also know that two measures of return are critically important to investors: Current Return on Equity (CROE) each year; and Total Return on Equity over the investment period, which financial economists call the Internal Rate of Return on Equity (IRRE). Therefore we create columns to the right to record these estimated returns. In this way, we construct the tables the reader will observe as Tables I and II. The returns recorded are not computed by equations, but by a complex computerized spreadsheet familiar to all students of real estate (McKenzie \& Betts, 2008). This spreadsheet may be structured in Excel $\mathbb{C}$, or in other similar spreadsheet applications. 


\section{Questions for Self-Directed Learning}

I call the reader's attention to Tables I and II. Table I presents the investment return data under different economic conditions, assuming that the Fixed Rate Mortgage (FRM) is used. Table II presents the same data assuming that the Adjustable Rate Mortgage (ARM) is used. Investment outcomes reflect the effects of mortgage rate changes over time for the ARM, and in both tables they reflect the effect that changing price levels (inflation) have on Net Rents.

Table 1. Key returns under possible economic conditions using the fixed rate mortgage option

\begin{tabular}{l|c|c|c|c}
\hline \multicolumn{1}{|c|}{ Possible Event } & Yr1 CROE & Yr2 CROE & Yr5 CROE & TOTAL IRRE \\
\hline Inflation $=1.0 \%$. FRM Rate, all years $=6.0 \%$. & $6.57 \%$ & $6.71 \%$ & $7.15 \%$ & $5.09 \%$ \\
\hline Inflation $=3.0 \%$. FRM Rate all years $=6.0 \%$. & $6.57 \%$ & $7.00 \%$ & $8.37 \%$ & $10.18 \%$ \\
\hline Inflation $=4.0 \%$. FRM Rate all years $=6.0 \%$. & $6.57 \%$ & $7.14 \%$ & $9.01 \%$ & $12.53 \%$ \\
\hline Inflation $=5.0 \%$. FRM Rate all years $=6.0 \%$. & $6.57 \%$ & $7.29 \%$ & $9.66 \%$ & $14.77 \%$ \\
\hline Inflation $=6.0 \%$. FRM Rate all years $=6.0 \%$. & $6.57 \%$ & $7.43 \%$ & $10.34 \%$ & $16.92 \%$ \\
\hline Inflation $=7.0 \%$. FRM Rate all years $=6.0 \%$. & $6.57 \%$ & $7.57 \%$ & $11.03 \%$ & $18.99 \%$ \\
\hline Inflation $=8.0 \%$. FRM Rate all years $=6.0 \%$. & $6.57 \%$ & $7.72 \%$ & $11.74 \%$ & $21.00 \%$ \\
\hline
\end{tabular}

Legend: $\mathrm{CROE}=$ Current Return on Equity. Total IRRE $=$ Total Internal Rate of Return on Equity (Total Return on Equity). FRM $=$ Fixed Rate Mortgage. The Rate for the FRM is $6.0 \%$ in all years. Rates of Return are computed in accordance with a standard computerized statement of cash flow commonly used in real estate investment analysis.

Table 2. Key returns under possible economic conditions using the ARM option

\begin{tabular}{|c|c|c|c|c|}
\hline $\begin{array}{l}\text { Possible Event } \\
\end{array}$ & Yr1 CROE & Yr2 CROE & Yr5 CROE & TOTAL IRRE \\
\hline $\begin{array}{l}\text { Real Rate Yrs } 2-5=3.0 \% \text {; Inflation }=1.0 \% \text {. } \\
\text { Nom. Mkt. Rates Yrs 2-5 =4.0\%. ARM Rate } \\
\text { Yrs } 2-5=3.0 \% \text {. }\end{array}$ & $8.11 \%$ & $11.33 \%$ & $11.77 \%$ & $9.11 \%$ \\
\hline $\begin{array}{l}\text { Real Rate Yrs } 2-5=3.0 \% \text {; Inflation }=3.0 \% \text {. } \\
\text { Nom. Mkt. Rates Yrs } 2-5=6.0 \% \text {. ARM Rate } \\
\text { Yrs } 2-5=5.0 \% \text {. }\end{array}$ & $8.11 \%$ & $8.54 \%$ & $9.91 \%$ & $11.63 \%$ \\
\hline $\begin{array}{l}\text { Real Rate Yrs } 2-5=3.0 \% \text {; Inflation }=4.0 \% \text {. } \\
\text { Nom. Mkt. Rates Yrs 2-5=7.0\%. ARM Rate } \\
\text { Yrs } 2-5=6.0 \% \text {. }\end{array}$ & $8.11 \%$ & $7.14 \%$ & $9.01 \%$ & $12.87 \%$ \\
\hline $\begin{array}{l}\text { Real Rate Yrs } 2-5=3.0 \% \text {; Inflation }=5.0 \% \text {. } \\
\text { Nom. Mkt. Rates Yrs 2-5 }=8.0 \% \text {. ARM Rate } \\
\text { Yrs } 2-5=7.0 \% \text {. }\end{array}$ & $8.11 \%$ & $5.75 \%$ & $8.12 \%$ & $14.11 \%$ \\
\hline $\begin{array}{l}\text { Real Rate Yrs } 2-5=3.0 \% \text {; Inflation }=6.0 \% \text {. } \\
\text { Nom. Mkt. Rates Yrs } 2-5=9.0 \% \text {. ARM Rate } \\
\text { Yrs } 2-5=8.0 \% \text {. }\end{array}$ & $8.11 \%$ & $4.35 \%$ & $7.26 \%$ & $15.35 \%$ \\
\hline $\begin{array}{l}\text { Real Rate Yrs } 2-5=3.0 \% \text {; Inflation }=7.0 \% \text {. } \\
\text { Nom. Mkt. Rates Yrs 2-5 =10.0\%. ARM Rate } \\
\text { Yrs } 2-5=9.0 \% \text {. }\end{array}$ & $8.11 \%$ & $2.95 \%$ & $6.41 \%$ & $16.57 \%$ \\
\hline $\begin{array}{l}\text { Real Rate Yrs } 2-5=3.0 \% \text {; Inflation }=8.0 \% \\
\text { Nom. Mkt. Rates Yrs } 2-5=11.0 \% . \text { ARM } \\
\text { Rate Yrs } 2-5=10.0 \%\end{array}$ & $8.11 \%$ & $1.56 \%$ & $5.58 \%$ & $17.79 \%$ \\
\hline \multicolumn{5}{|c|}{$\begin{array}{l}\text { Legend: CROE = Current Return on Equity. Total IRRE = Total Internal Rate of Return on Equity (Total Return on Equity). ARM = Adjustable } \\
\text { Rate Mortgage. The Nominal interest rate is the Market Rate, which is } 5.0 \% \text { in Year One. In accordance with the Fisher Theory of Interest Rates } \\
\text { Market Rate = "Real Rate" of interest + Anticipated Inflation. The Real Rate is assumed to be constant at } 3.0 \% \text { during the investment period } \\
\text { Rates of Return are computed in accordance with a standard computerized statement of cash flow commonly used in real estate investmen } \\
\text { analysis. Property Rents are assumed to change in accordance with general Inflation. }\end{array}$} \\
\hline
\end{tabular}

The data themselves suggest the right questions for students to consider. Instructors need not determine the appropriate questions in advance. The questions are not fashioned by financial theory; instead, they lead students into the theory - backwards. In fact, my reader could no doubt fabric an appropriate set of questions herself, even without a deep understanding of financial economics. But I will identify some of them anyway: 
Q \#1: Observe the returns reported for the FRM. As rates rise, it has little effect on Current Returns, but very large effects on Total Returns. How would you explain to an investor why it is that Total Returns are so much more sensitive to rising rates than Current Returns are?

Q \#2: Observe the effects on Current Returns that rising rates produce under FRM financing, and compare these with the effects observed under the ARM. They move in different directions! How would you explain to an investor why it is that rising rates are associated with opposite effects for the two loan options?

Q \#3: As rates rise, we see that this rise is associated with increased Total Returns under both mortgage options, but the effects are far greater under the FRM. How would you explain to an investor why that would be the case?

No doubt the reader can suggest other appropriate questions that would lead students to a deeper understanding of the financial economics underlying this important investment decision.

\section{CONCLUSION}

I present an approach to teaching complex theory in financial analysis at the collegiate and post-graduate levels that I call "teaching backwards". When teaching forwards in the traditional manner, instructors attempt to explain complex economic interactions that are often very difficult to explain and impossible to quantify. Students then plan financial reports designed to report the results of the preconceived theory. When teaching backwards, we minimize our attention to financial theory at the beginning, choosing instead to report the final outcomes that are important to investment decisions, varying the inputs that we believe will influence these outcomes. Students pay little or no regard to what they ought to expect these outcomes to be. Instead, they work backwards from a wide set of data output to identify patterns that reveal the effects of the cause variables upon the outcomes of interest. In this way, students study the impacts of theoretical cause variables in a self-directed manner, and may more easily observe their implications for business decision-making.

\section{AUTHOR BIOGRAPHY}

Dr. Robert Campbell is Associate Professor of Finance at the Frank G. Zarb School of Business, Hofstra University. He holds a B.A. from Yale University, an M.B.A. from the Wharton School, University of Pennsylvania, and a Ph.D. in Finance from the University of Connecticut. Dr. Campbell has published numerous research and financial theory papers in internationally recognized scholarly journals including Real Estate Economics, The Journal of Real Estate Finance and Economics, Financial Decisions, and others.

\section{REFERENCES}

Fisher, I. (1930). The theory of interest. New York: Macmillan.

Haney, M.H. (2016). Teaching the concept of investment risk through spreadsheet Monte Carlo simulations. Journal of the Academy of Business Education, 17, 236-256.

McKenzie, D. \& Betts, R. (2008). Essentials of real estate finance (5th ed.). Mason, Ohio: Cengage Learning, (Chapter 3). 